\title{
AULA-TRADUÇÃO DA DIFERENÇA: OS MÉTODOS ESPIRITOGRÁFICO E SONHOGRÁFICO EM TRANSCRIAÇÕES INTERCAMBIANTES
}

\author{
Maria Idalina Krause de CAMPOS ${ }^{i}$ \\ Sandra Mara CORAZZAii
}

Marina dos REIS ${ }^{\text {iii }}$

\begin{abstract}
RESUMO
Este artigo defende o uso efetivo de dois métodos na educação da diferença - o espiritográfico e o sonhográfico - como movimentos funcionais abertos que colocam em curso uma prática de aulatradução. Mostra que as pesquisas efetivadas por meio de escrileituras (leitura-e-escrita) possibilitam transformar os conhecimentos de um espírito que sonha em transcriações de nova escrita, criando sua própria realidade nas cercanias da linguagem curricular. Conclui que uma aula-tradução se afirma como uma poética disparadora de sentidos que dão a ver uma didática da invenção, afeita aos sonhos e às aventuras do intelecto na agoridade do magistério contemporâneo.
\end{abstract}

PALAVRAS-CHAVE: Escrileitura; Tradução; Aula; Métodos.

DIFFERENCE TRANSLATION-CLASS:

THE SPIRITOGRAPHIC AND DREAMGRAPHIC METHODS IN INTERCHANGING TRANSCREATIONS

\begin{abstract}
This paper advocates the use of two methods in education of difference - the spiritographic and dreamgraphic ones - as open functional movements that trigger a practice of translation-class. It shows that researches carried out by means of reading-writing have enabled the transformation of knowledges of a spirit that dreams into transcreations of new writing, thus creating its own reality around the curricular language. It concludes that a translation-class is affirmed as a poetics that triggers meanings, which evidence a kind of didactics of invention related to dreams and adventures of the intellect in the nowness of contemporary teachers.
\end{abstract}

KEYWORDS: Reading-writing, Translation, Class, Methods.

i Doutorado em Educação pela Universidade Federal do Rio Grande do Sul. Pesquisadora da Rede de Pesquisa Escrileituras da Diferença em Filosofia-Educação (UFRGS). E-mail: idalinakrause@ yahoo.com.br - ORCID iD: http://orcid.org/0000-0002-0016-7455.

ii Doutorado em Educação pela Universidade Federal do Rio Grande do Sul. Pesquisadora de Produtividade 1B do CNPq (2020-2021). Coordenadora da Rede de Pesquisa Escrileituras da Diferença em Filosofia-Educação (UFRGS). E-mail: sandracorazza@ terra.com.br - ORCID iD: http://orcid.org/0000-0002-1237-198X.

iii Doutoranda em Educação pela Universidade Federal do Rio Grande do Sul. Pesquisadora Colaboradora da Linha de Pesquisa Filosofia da Diferença-Educação (UFRGS). E-mail: mdr@ufrgs.br - ORCID iD: https://orcid.org/0000-0002-2088-5358. 


\begin{abstract}
RESUMEN
Este artículo defiende el uso efectivo de dos métodos en la educación de la diferencia - el espiritográfico y el sueño-gráfico- como movimientos funcionales abiertos que colocan en curso una práctica de clase-traducción. Muestra que las investigaciones efectivizadas por medio de la escrilectura (lectura y escrita) permiten transformar los conocimientos de un espíritu que sueña en recreaciones de una nueva escrita, creando su propia realidad en las cercanías del lenguaje curricular. Se concluye que una clase-traducción se afirma como una poética disparadora de sentidos que revelan una didáctica de la invención, acostumbrada a los sueños y a las aventuras del intelecto en el ahorismo del magisterio contemporáneo.
\end{abstract}

PALABRAS CLAVE: Escrilectura; Traducción; Aula; Métodos.

\title{
1 INTRODUÇÃO
}

Este artigo trata de dois métodos de transcriação no fazer magistral contemporâneo. Operacionalmente entremeados, os Métodos Espiritográfico (CAMPOS, 2017) e Sonhográfico (REIS, 2019), funcionam como disparadores para pensar o pensamento nas vias da transcriação do sonho didático e da poesia curricular (CORAZZA, 2019a). Com aportes da Filosofia da Diferença-Educação, o texto apresenta a temática em três eixos: a) Método Espiritográfico de perspectiva valéryana, que toma o conhecimento como invenção por meio de escrileituras; b) Método Sonhográfico que transcria sonhos de arquivos a-traduzir no espaço-aula; c) A problemática: como aplicar tais métodos?

O texto, portanto, se deslocará entre os três eixos propostos, para assim dar a ver a construção de uma poética que dispara sentidos e que se ativa como força propagadora para uma criação autoeducativa e que se afirma entre o currículo com suas unidades analíticas: EIS (Espaços, Imagens e Signos); e a didática com suas unidades analíticas: AICE (Autor, Infância, Currículo, Educador).

Afirmando que a produção do trabalho docente no cotidiano necessita sempre de um exercício empírico de um espírito escrileitor que oficina pensamentos, valendo-se da linguagem e dos sonhos para construir ou transcriar conhecimentos a partir de si, e que tem sua ocorrência laboral em uma Aula-tradução ou em oficinas de transcriação. 
Nessa Aula-tradução os signos envolvidos no fazer docente emergem dos sonhos (individuais e coletivos), das vidas diurnas, da própria Aula e dos Arquivos nela manipulados. Tudo é potencial matéria em movimento no que tange a currículos e didáticas e dos encontros que com eles estabelecemos. E nesse deslocar-se, faz emergir uma poética da sensibilidade perceptiva, que passa a ser grafada com a mão que rabisca sonhos, e que ocorre em revezamentos mutantes entre currículo (EIS) e didática (AICE). Nessas condições, como enfatiza Corazza (2013, p. 219), ocorre à tradução de determinada matéria-arquivo, que cria novos arquivos sonhados, "para além do literalismo rudimentar e da banalidade explicativa".

Os dois métodos supracitados configuram-se em processo compositivo de escrita, oriundo de pesquisas individuais e coletivas de dois projetos e vinculadas ao Grupo de Pesquisa do CNPq, Escrileituras da Diferença em Filosofia-Educação, coordenados pela Profa. Dra. Sandra Mara Corazza, quais sejam: 1) Didática da Tradução, Transcriação do Currículo: Escrileituras da Diferença (2015-2019) que investiga um currículo e uma didática da diferença; 2) A-traduzir o arquivo em aula: sonho didático e poesia curricular (2019-2023), "pesquisa [...] acerca da tradução onírica do arquivo de Aula, constituído pelo Currículo e pela Didática [...]” (CORAZZA, 2019a, p. 4). Ambos os projetos visam prosseguir, correlacionar, complementar e consolidar a formação de professores-pesquisadores.

\section{MÉTODO ESPIRITOGRÁFICO}

O Método Espiritográfico é concebido a partir de pesquisas da vida e da obra do poeta e pensador Paul Valéry. Esse pensador secular de vasta e eclética produção de escrita tem apreço especial pelos movimentos de pensamento, às invenções do intelecto enquanto possibilidade para pensar o próprio pensamento. Ou seja, verificar o funcionamento das operações do espírito, seu processo de construção intelectiva para fins de conhecimento.

Conhecimento que passa necessariamente pela linguagem e pelo exercício rigoroso de escrileituras - leitura pela escrita e escrita pela leitura - conceituada como um plano extenso e aberto que serve para a formação e para um fazer docente, na medida em que mescla conhecimento e linguagem. Colocando em movimento funcional, prático e construcionista um espírito em sel-variance (variação de si) manipula arquivos e que rabisca nova escrita, 
impulsionada pela paixão (pathos) que nos joga para fora de nós mesmos através de uma atividade estética que mescla o sensível e o inteligível em suas infinitas gradações.

Engendra-se desta maneira na didática e no currículo da diferença, uma vontade de expressão, ligada às sensações, que são experienciadas em novos traçados compositivos de escrita espiritográfica. Colocando em funcionamento uma concepção secular de escrita que serve ao campo da educação como um desafio tradutório, uma empiria poética sempre em mutação, que se afirma e se atualiza entre fluxos e entre-fluxos da linguagem que constitui um arquivo a ser explorado e por via de consequência transcriado. Pois, como pondera Valéry (1941a, p. 188) “é perfeitamente inútil um saber que não posso modificar”.

O Método Espiritográfico foi concebido como uma maneira de ler e interpretar à realidade, onde Corpo-Espírito-Mundo (CEM) encontra-se sempre em ação funcional. Pois, como afirma Valéry (2011, p. 215) "tudo passa entre o que denominamos o Mundo Externo, o que denominamos Nosso Corpo, o que denominamos Nosso Espírito". Abre-se assim, um campo educativo virtual, ficcional e tradutório onde o espírito se encontra consigo mesmo e também com suas circunstâncias de mundo, num determinado tempo e espaço, passando a funcionar em atravessamentos entre a realidade e o sonho. O que possibilitam a nossa sensibilidade criar itinerários singulares e assim levantar problemas que digam de nossas inquietações mais prementes, visto que "[...] é o que contenho de desconhecido a mim mesmo que me faz ser eu mesmo" (VALÉRY, 1997, p. 59).

Nesse processo rumo ao desconhecido - do ainda não visto - o Método Espiritográfico serve como um mecanismo de composição de escrita e no espaço-aula. E efetiva-se como um jogo poético, como um disparador tradutório de arquivos no campo da educação, através do manejo de matérias tanto da arte, como da ciência, como da filosofia. Possibilitando a germinação de uma escrita-artista e que desvia da trivialidade da mera transmissão de conhecimentos. Pois a ela interessa a escrileitura como meio de produção de escrita, mas do que como um fim ou como uma meta.

Sendo assim, a riqueza do pensar está no processo mesmo de composição, de uma tradução que faça com que o pensamento se coloque em uma dobra especular diante de um determinado arquivo, em que ele possa se perceber em processo, em uma ação de mutação de saberes. Isto é, como ato de criação permanente, num exercício que preza as aventuras do intelecto. Tais aventuras se valem de um sistema plural de linguagens (diálogo, prosa, verso, 
tropos) onde o espírito exerce suas alquimias numa ação de montagem e desmontagem de escrita, contrária a anestesia do gesto e prezando um operar errante em constante variação

Por esse motivo, ressalta Valéry (2011, p. 110) “eu sei apenas o que sei fazer" ciente da importância de o espírito dedicar-se a observar e analisar a gênese e os processos das obras humanas, acompanhando a par e passos, os espíritos que criam, utilizando-se da imaginação, mesmo que de um modo conjetural, na construção de uma Comédia do Espírito ou do Intelecto. $\mathrm{Na}$ medida em que se interpretam ou mesmo se criticam obras alheias, cria-se por essa via um modo de também meditar e pensar sobre si mesmo, de maneira que, interpretar é também interpretar-se.

Nesse fazer é necessário Le plaisir de faire (o prazer de fazer); um jogo como ação de pensar que compõe uma escrita poética; que cultiva uma Ofis-Sofia autofecundante para uma educação espiritual que preza os movimentos antropofágicos de um serpensamento e que como o Ouroborus, - a serpente simbólica - devora-se a si por meio de um pensar círculo vicioso, um eterno retorno, porém nunca ao mesmo estado original que deu início ao processo.

Durante o percorrido de pesquisa foi possível à criação de onze tipos de espiritografias (CAMPOS, 2018), utilizando o Método Espiritográfico e que lidam com matérias da arte, da ciência e da filosofia por intermédio de escrileituras com perspectiva valéryana e que toma o conhecimento como invenção. Aqui traremos somente um exemplo de um tipo de espiritografia criada, em função do espaço permitido à composição do artigo.

\subsection{Espiritografias do extraordinário: aula-tradução}

O subterrâneo é um tipo de espiritografia em que o estilo de texto visita Edgar Allan Poe e suas Histórias extraordinárias (1978) e Jorge Luis Borges (2007) com O livro dos seres imaginários. Investiga também um mapa de Porto Alegre de 1839 como um território onde se verifica a possível localização de um prédio, bem como seu possível andar subterrâneo.

Os seres imaginários apresentados têm como disparador de escrileituras alguns verbetes do Dicionário de símbolos de Jean Chevalier (1998). Tais verbetes constituem as personas dos personagens criados, que podem, a qualquer momento, avançar em certa direção, apelando a elementos e saberes utilizados em outras especialidades, como: mitos, sonhos, costumes, gestos, formas, figuras, cores, números. 
O que se busca com esse experimento é registrar um estado de um espírito que se afeta pela leitura e pela imagem e com elas escreve a sua espiritografia. Essa ação de fazer, construindo um texto, analisa e descreve o funcionamento da inteligência criadora de seres de espírito, isto é, Poe e Borges. Tem-se como disparador o que nos diz Valéry (1941b, p. 107): "os homens se diferenciam pelo que mostram, e se parecem pelo que escondem". E os espaços em que habitamos: o que mostram? O que escondem?

\section{O subterrâneo}

Se houvesse um livro da imaginação e da emoção provocada por ela no intelecto, teríamos de nos deter nas pequenas coisas extraordinárias do cotidiano que notamos e que servem como disparadores acidentais de um imaginário. São detalhes que nos chamam a atenção e aos quais anteriormente éramos indiferentes. Não espero nem peço que se dê crédito à história sumamente fantástica e, no entanto, bastante corriqueira que passo a narrar. Insana seria eu se esperasse tal coisa, tratando-se de um caso de um prédio assombrado que meus próprios sentidos se negam a aceitar. No entanto, louca não estou e, com toda certeza, não sonho acordada. Mas um dia, a morte me levará, e, por isto, agora decidi aliviar meu espírito e a história contar.

Meu propósito aqui é apresentar uma série de acontecimentos que me aterrorizam, mas ao mesmo tempo me distraem, dando asas à minha imaginação. No entanto, não escrevo com intuito de esclarecer o que passa. Apenas dizer que são estados produzidos em minha psique, que tende, muitas vezes, ao grotesco e ao bizarro. Talvez, mais tarde, haja alguma outra inteligência que também possa ter passado por isto, que seja talvez mais lógica e menos excitável que a minha.

Pois desde o início de meus estudos, frequento este prédio, ouço vozes estranhas quando me encontro sozinha pelos corredores. Já senti rajadas de vento em salas totalmente fechadas, tive a impressão de olhos me observando dentro do box dos microbanheiros, já me senti acompanhada no pátio, mesmo andando "sozinha", já espirrei na biblioteca, e alguém disse "saúde!", mesmo eu estando entre prateleiras de livros somente. Enfim, uma série de eventos vem me acompanhando desde que coloquei os pés em seu saguão de mármores desgastados.

Certo dia, ao chegar ao prédio, bastante cansada pelas minhas andanças de estudante pelo campus, tive de súbito a impressão, ao subir no elevador, que ele se tornara para mim um 
objeto e um lugar misterioso, destacando-se, naquele momento, da desordem comum do cotidiano da faculdade. Admitamos que olhar uma caixa chamada de elevador com olhos fecundos da imaginação estimula o espírito a uma produção vertiginosa de conjecturas, o que instala certa apreensão. A tal caixa-elevador sobe e desce há décadas, para comodidade de corpos humanos que se deslocam por seus andares, o que prende a atenção de meu espírito por um lado. Mas ele causa também em meu espírito manifestações de um imaginário. Detenças súbitas de tudo o que pode haver de inumano e de esquisito nos seres que se suspendem e que eu observo nessas viagens entre andares.

Este elevador que escolhi neste prédio e que observo me oferece uma ideia de uma existência outra - a de um possível subterrâneo também imaginário. Em princípio, a ideia parece esdrúxula, mas o essencial aqui, contudo, é que a matéria narrada reflete a captura de pequenos indícios, detalhes singulares e inimitáveis que presenciei nas idas e vindas e que retratam criaturas num espectro múltiplo de anomalias. Entrementes, o subterrâneo por mim imaginado restabeleceu minha crença na vidência, em que não há certezas, mas nebulosas que geram certo pânico e horror, mas também abertura a certa comicidade.

Uma noite em que me achava sentada, meio aturdida, debaixo das árvores em frente ao saguão, tive a atenção despertada novamente e subitamente pelo elevador. Fazia alguns minutos que olhava fixamente para ele enquanto fumava um cigarro, e o que me surpreendeu foi não ter visto antes o que agora via. Aproximei-me e toquei-o com a mão no botão para acioná-lo, pois precisava ir até o sétimo andar encaminhar alguns documentos.

Dentro da caixa, apertei no sétimo, e foi subindo, ao menos esta era a sensação. Quando o número 7 digital ficou vermelho anunciando o andar, houve um barulho de cabos de aço e um tremor sentido nas solas de meus pés. Uma parada total e silenciosa, seguida de uma queda vertiginosa, veloz e surpreendente, até uma nova parada suave como se a caixa tivesse caído em uma montanha de algodão.

A porta se abriu para outro saguão. Diante de meus pés, ainda trêmulos, sobre um piso envidraçado, era possível ver o que pensei ser, em função da vastidão do que via, nove andares subterrâneos. Uma estranha alquimia! Nas transparências de tudo o que via e maravilhosamente espantada, observei salas e espaços ocupados por seres dos mais variados, espíritos que desde a inauguração do prédio o frequentaram de uma maneira ou outra. Estranhos entes engendrados 
com que se pode brincar, em função de suas "formas cambiantes reveladas por um caleidoscópio" (BORGES, 2007, p. 10).

De minha parte, passei a sentir logo um deleite por tudo o que acontecia em meu imaginário vivível. Na verdade, naquele momento, eu era uma "agraciada" de pele arrepiada - um ser que ia além do cotidiano numa aventura intrigante. Era a própria louca da imaginação, uma besta-fera sedenta em fazer contato com tais seres extraordinários. Suspirei o mais fundo que pude e disse de mim para mim: Oh, grande e misterioso evento! Ai de mim! Vou me perder em pensares dúbios, é certo!

Então, passo agora à compilação, por certo incompleta, de alguns seres desse subterrâneo imaginário, pois sua multiplicidade vai ao infinito. Talvez, penso eu, porque assim como é em cima é também embaixo, ou seja, uma estranha alquimia há nisto tudo.

\section{A Apsara ou calourus pedagógicus}

Tal criatura é amante dos cortejos, cursinho, vestibular, até tornar-se caloura da pedagogia e quase sempre ocupando um papel angélico. Tal papel cai por terra, e ela deixa ver seus demônios quando pinta a cara e é recebida como bixo na faculdade que irá frequentar. Seus encantos vêm de sua origem de dançarina e cortesã celeste, pois na infância dançava balé, em que girava com uma saia tutu rosa bebê. Amorosa como as mensageiras de Kali, desde infante, convoca os homens ao amor da Divindade. É identificada na Índia como divindade do jogo da carne, e não é diferente no Brasil, pois agora a Apsara entra no jogo pedagógicus. E qual dança agora ela dançará neste carnaval?

\section{Beemot-trans ou ser intelectual}

Na verdade, este boi é um hipopótamo, ou melhor, um ser intelectual. Quando chega, causa alvoroço aos néscios que com ele comem feno das mil montanhas. Porém, não moram nas montanhas, mas sim sobre a flor de lótus. De características animalescas e irracionais, não teme em usar a força bruta para conseguir seus intentos. Mesmo correndo o risco de poder servir de alimento acadêmico nos festins solenes e místicos, onde será degustada sua carne farta e seu cérebro vinagrete oferecido aos convivas.

Ndu ou Bellus 
Considera-se um gênio superior que tem o cupinzeiro como residência, principalmente se ele estiver localizado dentro de uma sala qualquer. Lá se instalará e irremediavelmente lhe fará companhia fiel. Bellus acha que garante, orienta e protege as colheitas de seu próprio cupinzal, vendo-se, portanto, como uma garantia de riqueza, educação e gentileza. Considera que o cupinzeiro também possui uma função protetora, erótica e prazerosa. Talvez pela atividade subterrânea dos insetos, coloque-os em ligação com as nefastas influências provindas do fundo da terra cupinzal. Um deleite onde Bellus pensa reinar absoluto como Shazam.

Tal Espiritografia do extraordinário, posta a funcionar em uma Aula-tradução, passa a ser escrita, ao sintonizar os atos tradutório-autorais dos alunos que em novos corpos linguísticos estabelecem relações com a vida no contemporâneo, pois na medida em que se faz, exercita interrogar-se: se tudo o que disse, até então, é tudo o que pode dizer; se tudo o que viu, até agora, é, de fato, tudo o que pode ver; se tudo o que pensa é tudo o que pode pensar; se tudo o que sente é tudo o que pode sentir; se tudo o que traduziu é tudo que pode traduzir neste lugar chamado de espaço-aula hoje.

\section{MÉTODO SONHOGRÁFICO}

Sonhografar é um tipo de transcriação pela vontade intempestiva que vibra o corpo do docente-poeta-tradutor. Isso o leva a perspectivar ficções de Aula em suas traduzibilidades e deixando rastros a-traduzir, que é o tipificador da tradução, aquilo que escapa da passagem comunicativa interlingual, ao mesmo tempo, é a ferramenta do tradutor que, na transcriação, transforma o simbolizante no simbolizado. Pois, empiricamente valores criam-se qualitativamente, num jogo vivo e diferencial, maquinado pela elaboração secundária (FREUD, 2005; 1996), já que o sonho segue a boca, contar uma Aula, é sonhar currículo e poetizar didática.

Sonhografias de Aula são transcriações poéticas que perspectivam unidades constituídas pela fusão de contrários: um sonho, uma aula, são composições de fragmentos de tudo o que não é nem sonho e nem aula: "o poeta fala das coisas que são suas e de seu mundo, mesmo quando nos fala de outros mundos: as imagens noturnas são compostas de fragmentos das diurnas, conforme outra lei” (PAZ, 2015, p. 55). 


\subsection{Sonhografia: aula-tradução}

A tradução de um sonho didático é perspectivada sobre a linguagem em sua profusão imagética e pela força de ilogismos. Tal método operacionaliza-se na recriação de um campo pós-imaginário, cavalgando num pensamento sem imagem. Tarefa infinita e de cuidado, utiliza autores diversos do Arquivo da Educação para desenvolver seu plano sonhográfico como poesia curricular. E sendo assim, na feitura de uma sonhografia, são admitidas as mais diversas incorporações - fragmentos do imprevisível e intraduzível a-traduzir que se transcria, porque o próprio Método Sonhográfico se constitui como sonhografia.

A relação produtor/consumidor na educação poética de Valéry (CAMPOS, 2018) ensina-nos que o leitor saberá provavelmente que se trata de uma leitura em sonho e sobre sonho, mas a sua tradução e interpretação, uma vez contaminado, assim escrileitor, passará a sonhografar outros níveis de reelaboração poética. Não se trata, ao sonhografar, de tomar a matéria e contar uma história alusiva ao original, ou de transformar o original numa incógnita indecifrável, mas de polarizá-la até o nível da alucinação, tomando os cuidados com a dupla articulação que ocorre no espírito, que separa e identifica da matéria as suas partes a-traduzir e que, pelo crivossonho, suspende fragmentos a-traduzir e aplica-lhes uma elaboração onírica.

Na poética sonhográfica, quem sonha avalia e interpreta as figuras, para que se trate de um sonho. Anunciada a poética do sonhador, que luta com essas formas e contraformas, o homem joga com o real assim como um escultor — diante de um bloco de mármore - joga com o sonho sobre o real.

O fazer sonhográfico oscila entre o sonho e o real submetido ao sonho do docente artistador, que molda o Informe (CORAZZA, 2013) ou seja, traduz as imagens poéticas que sua imaginação sonha ao entrar em contato com o real das partes a-traduzir do Arquivo, estando, portanto, num estado de labor onírico e aderente às seguintes forças de transcriação inerentes ao "direito de sonheria docente" (CORAZZA, 2019a):

a) Palavras com potenciais imagéticos, não decalcadas em silogismos linguísticos, a sonhografia é exercício de imaginação ativa. As palavras poéticas possuem empilhamentos de significados, as sonhografias propõe assim uma prática da escrita a partir de sonhos, por ser 
material flexível, acessível, ininterrupto, e instantaneamente desejoso de ser contado (traduzido) e/ou interpretado e escrito;

b) Não há um referencial prévio, mas nova língua didaticadora: poetar, criar a sua docência, seus cânones literários, dar o seu sotaque ao que traduz, artesania que tece um texto com a marca da mão (CORAZZA, 2013);

c) Escrita que admite rupturas, assertividades, estranhamentos, coragem, sustos, não pautada numa metafísica da presença, ou da perfeição ou imperfeição, tampouco no platonismo que busca descobrir o verdadeiro diante do falso;

d) Dramatiza-se em simulacros: suas imagens borradas, perdem materialidade, ganham velocidade (REIS, 2019 b), rompem as imagens-prontas, bocejam aulas-sonhos. a sonhografia como uma maneira de criar velocidades no pensamento em microrrupturas de atravessamentos, não estagnando-se em uma imagem dogmática do pensamento;

e) Pensa a educação transcriadora do arquivo numa evocação/impressão por sensações, afetos. Emoções são signos que incitam processos psíquicos de sentimentos e, por fim imagens. Traduzir na escrita a partir do sentimento e de suas partes a-traduzir;

f) Pensa artistadoramente a vida inseparável do fazer-se professor escrileitor;

g) Volta-se às culturas míticas, sem desconectar-se das teorias tradicionais sobre sonhos, para transvalorar novas formas de fazer didática;

h) Aulas-sonho: construção de tessitura textual, transindividual (CORAZZA, 2019b), sonhos individuais em revezamentos com sonhos coletivos;

i) Pensa pela língua imperfeita do tradutor onírico: o sonho fala a língua ancestral, simbólica, imagética, somos vítimas de nós mesmos nessa existência onírica, narrar, escrever, sonhografar um sonho, em associações, inversões, amplificações, compensações, transformações diante do original é uma língua poética, da docência, sempre incompleta e desejosa;

j) Admite-se, no Arquivo e na vida, não apenas o passado, mas amplificações criativas atreladas às teorias, ao arquivo da educação, a fim de criar possibilidades de novos signos, cujo sentido será o da poética circulando entre as várias perspectivações e não em um empobrecimento linear e fatalista histórico; 
k) Não há a dicotomia vida diurna e vida noturna: a lucidez é resgatar a sensibilidade da vida onírica também cotidianamente, com seus sinais que não cansam de se inscrever nos copos de Aula;

1) Não se transcria para informar, distrair, comunicar, ilustrar. O trato com o informe passa a fazer parte do processo pensamental de escrileitura, de modo aberto, admitindo ilogismos, matérias a-traduzir como uma obra de arte, sem a geração e a preocupação de interpretoses;

m) Trata-se de valorar numa perspectiva crítica a docência-pesquisa de sonhos, a realidade como deveniente. A vida é imanência de velocidades caóticas, para dela transcriarmos novas molduras (maleáveis) em ficção de sonho e poesia, contando com rigor intelectual (via espiritografias);

n) Admite o corpo como suporte e fundo falso das possibilidades de uma vida que se transcria, a cada dia, assim como os sonhos refazem-se, repetem-se, diferenciam-nos e nos reaproximam de nós e das formas de expressão com a realidade;

o) Não há ressentimento ou culpabilização por quadros oníricos indesejados ou angustiantes, pesadelos etc. Perspectivando-se pela literatura (sintomas do mundo), o professorpoeta tipologiza topologicamente suas dificuldades de tradução fazendo dela uma realização. Sonhografar a tradução neuronal das vontades celulares e inconscientes;

p) O corpo é a referência do nosso mundo (FOUCAULT, 2010) e dos sonhos: o sonho nos mostra o que se passa em nossas costas, recuperá-lo é desterritorializar pulsões, nessa prática de si, a escrita é ato de criação, não apenas tentativa de realizar desejos ou de facilitações ao fim de traumas, é escritura da Diferença;

q) $\mathrm{O}$ texto sonhográfico passa a conectar-se rizomanticamente aos mapas mentais do intelecto, paisagens de transcriação, novas maneiras de abordar a matéria, entendendo também a função social dessa desterritorialização promovida pela troca de sonhos na Aulatradução;

r) A educação pelos sonhos está no contexto da abordagem estética, estética do inconsciente, ou seja, há mínimos fragmentos prontos a ser transcriados em coletivo pelas multiplicidades das inteligências, não hierarquizadas pelo poder imediato do detentor da fala (RANCIÈRE, 2009); 
s) As sonhografias admitem as sombras, as cores emocionais, os elementos alquímicos, as transvalorações, as composições, o obscuro que está presente em qualquer sonho, e que, ao estudarmos os sonhos, estamos estudando como o pensamento se forma em suas profundidades deformadoras, condensadas e deslocadas;

t) Nos exercícios sonhográficos, pensar o informe (CORAZZA, 2013), as emoções, suas figurações, o grito, o balbucio, as formas primitivas não-linguais, uma tradução nunca literal. Proporcionar uma leitura de interstícios, de tramas entre filosofia, artes e ciências, criar a riqueza às possibilidades de escritas e didáticas, pela consciência de uma vontade de sonho em trânsitos poéticos;

u) A sonhografia realiza-se como prática de si que afirma a vida, não amortiza a tarefa docente à uma comunicação informativa, transvalora o professor como poeta e artistador, o preparo de aula em escrituras e não em ícones representativos. Sonhografia inaugura-se como experiência de vida estética e plurívoca tradutória;

v) Admite que - o imaginário forma o real. Como operação prática, deve-se anotar o quanto antes os sonhos, as emoções, as cores, os movimentos, as sensações, atentar aos microssinais intervalares durante a escrita e a narrativa, usar do rigor espiritográfico que se instala entre o jogo de forças do informe com a tarefa de Aula-tradução;

w) Usar do restauro ficcional associativo, amplificativo, mas também intercambiálos às vivências de escrita-docência;

x) Nesse procedimento, por fim, há de se considerar as estruturas dos quadros imagéticos e não apenas a materialidade das figuras.

Os fragmentos acima compõem o bloco inicial do método. Sonhografar é exercício de repetição, cria viações cerebrais novas, como prática de imaginação, memória, há a elaboração que desdobra a condensação poética quando se pratica o caminho de retorno ao sonho.

O Método Sonhográfico traduz a imagem-sonho pelo caleidoscópio da Diferença, ou seja, é ato que deixa seus rastros singulares ao riscar os padrões e cenas que são evocados pelo pensamento inicial, para tencionar a tendência do espírito (intelecto) a imitar e imprimir imagens mentais do que o corpo sente. Considerando essas forças cerebrais de ativaçãoreativação-retorno, e avança no espaço dispositivo do cérebro, ou seja, o não-lugar do arquivo do intelecto, tipo de memória celular que recolhe absolutamente tudo o que vemos, sentimos e somos, consciente e inconscientemente. 
Considera também que a mente usa o espaço da imagem para engendrar padrões. A seguir, o Método Sonhográfico é tomado pelo rigor do espírito valéryano (VALÉRY, 2018; CAMPOS, 2013, 2018;), pois seleciona zonas de potência caótica e fluida do Informe (CORAZZA, 2013). Essa seleção verte-se num plano de escrita que passa a atualizar perspectivando núcleos virtuais de a-tradução, sem imagem pré-estabelecida, e refuta ativamente imagens aleatórias ao ritmo estabelecido de determinada sonhografia.

A elaboração sonhográfica luta constantemente com aquilo que o original traduz literalmente, pois é o que não se sonha. Um sonho é feito de tudo o que não é sonho, uma tradução é transcriada de tudo o que não é do original. Ao mesmo tempo, luta com aquilo que turbilhona o pensamento pela artistagem inconsciente.

Se eu sonho com uma árvore e um cão farejando atrás dela, posso sentar-me em sua sombra e me apoiar no tronco que crio ao sonhar, assim como posso seguir o cão, e a árvore ficará então em uma distância, em segundo plano. O cão cava um buraco onde outro cão e não uma árvore brota. É possível identificar um original? A sonhografia não abandona o original, mas poderá, portanto, deixá-lo diluído ou em segundo plano no conteúdo manifesto. E às vezes em regime latente, que expressará estética manifesta diversa do original.

Ao sonhografar, o docente afirma a sua singularidade e individuação de tradutorartistador, que combinou à capacidade semiológica a capacidade afetiva e original de ler a matéria do sonho alheio, na sua liberdade sensível de não homogeneizar as partes a-traduzir e sim de evocar, poeticamente, outros elementos para a composição. Onde novos valores são criados quando o sonho do outro ou o meu é sonhado de novo. A cada leitura de uma sonhografia, há desterritorialização do sonho de partida, que é repovoado no sonho de chegada, pela invenção poética da perspectiva do leitor-escritor.

$\mathrm{Na}$ sonhografia isto funciona no processo de instalar o plano poético do sutil a tudo o que faz ou pensa, sem esmaecer sua vontade de vivenciar detalhes, de viver alhures. Ainda, não há dados, as partes a-traduzir são derretidas, reviradas, associadas aos pontos psíquicos do sonhografista, e remodeladas pela ressemantização materializada em "sonhos de tinta" (CORAZZA, 2019a) diante do Arquivo. A relação tradutória é diferencial, nos força a sonhar pela diferença.

A relação produtor/consumidor na educação poética de Valéry (CAMPOS, 2018) ensina-nos que o leitor saberá provavelmente que se trata de uma leitura em sonho e sobre 
sonho, mas a sua tradução e interpretação produz-se escrileitor, o qual passará a sonhografar outros níveis de reelaboração poética. Sendo assim, o Método Espiritográfico associa-se colaborativamente com o Método Sonhográfico funcionando como um centro da força lógica do ego vígil, que aceita a transalucinação quando da sonhografia, para que um drama possa ser avaliado e interpretado a partir das partes mais estranhas e intraduzíveis daquilo que elegemos tomar como ponto zero da criação, o umbigo sonhográfico. Isso porque, usamos da linguagem conceitual vígil, mas também aos esquemas da imaginação do sonho, permitindo que a tradução tenha espaços vazios, espaços a possibilidades de invenção, uma atividade não representativa de imagem de pensamento, mas inspirados esboços de vida e de potência que sente as partes do corpo quando da transcriação e dali também alucina novas paisagens.

Não se trata, ao sonhografar, de tomar a matéria e contar uma história alusiva ao original, ou de transformar o original numa incógnita indecifrável, mas de polarizá-la até o nível da alucinação (e não da alienação), tomando os cuidados com a dupla articulação que ocorre no espírito (intelecto), que separa e identifica da matéria as suas partes a-traduzir e que, pelo crivossonho, suspende fragmentos a-traduzir e aplica-lhes uma elaboração onírica.

O material onírico, que nos parece muitas vezes uma criação artística e surpreendente, possui evidentemente a memória como ativadora das imagens que transformamos no fazer do sonho, mas esse comando parece-nos inacessível de realizar na vigília. O método sonhográfico deseja ativar essa percepção vígil, pelos exercícios sonhográficos (REIS, 2019a) e usando o rigor do pensamento valéryano quando do acesso a essas evocações do sonho, e podemos perguntar a esse sonho evocado, por exemplo, se nossas paixões de espírito estão ali simbolizadas, ou realizar um esforço de memória de nossos últimos dias.

Segundo Freud (1996, p. 55) as lembranças cotidianas mais evidenciadas na construção dos sonhos são aquelas que na vigília não estão sob nossa extrema atenção e que as lembranças de dois dias atrás estarão mais presentes do que a do dia imediatamente anterior. Esse trabalho mental nos interessa ao longo do desenvolvimento do método sonhográfico. A evocação, na vigília, de um sonho, exige o rigor de pensamento valéryano, pois o sonho é uma versão de uma ideia, uma forma também de pensamento. Para que possamos trabalhar o pensamento sobre uma evocação onírica, não apenas usar a faculdade superior da memória e da lógica consciente é necessário usar o rigor de espírito sombrio na elaboração da transcriação sonhográfica. $\mathrm{O}$ material onírico, mesmo sendo oriundo do inconsciente, em sua evocação passa pelo crivo da 
mente consciente. Mas a mente desperta não mantém um curso regular e livre de inúmeros outros pensamentos, imagens, e representações que constantemente é preciso refutar para que se possa pensar, dar a pensar.

O sonho e a escrita realizam um trabalho semelhante, uma dobra de pensamento. Deste trabalho tradutório, por exemplo, podemos sonhografar mesmo a partir de uma palavra tomada do Arquivo, de sua raiz e de suas sonoridades, recriar um universo próprio a partir de um significante. Essa transalucinação sobre partes do arquivo baseia-se nas constatações freudianas (FREUD, 1996, p. 94) de sonhos delirantes, em que as imagens sonhografadas ligam-se entre si pelas associações de analogias sonoras. Isso nos leva a um caminho poético. O trabalho valéryano neste caso evitará o total delírio, pois esse jogo tradutório manterá vínculos artistadores com o original, numa perspectiva de distanciamento, seguindo a voz das palavras, suas cadências no idioma, ou mesmo de outro idioma, e nelas tensionando ou relaxando o seu vínculo com o original.

Atualiza-se esse virtual inconsistente do Arquivo pelo crivossonho: acontecimento sonhográfico sobre a massa confusa onirofílica de a-traduzir, marcando-se o ponto zero pela tinta negra. O crivossonho é a passagem que só existe no ato tradutório, realizado pelo corpo do sonhografista cujas microssensações são traduzidas pelos músculos conscientes, que escrevem realizando-se em amplificações dessas vontades, quase sempre com tessituras poéticas.

\section{COMO APLICAR TAIS MÉTODOS?}

Na prática da docência-pesquisa, colocamos a funcionar esses dois métodos pela primeira vez em uma ação conjunta para a formação de professores, a qual envolveu nosso Grupo de Pesquisa em Filosofias da Diferença-Educação (UFRGS), coordenado pela pela Profa. Dra. Sandra Mara Corazza, em parceria com a Secretaria da Educação de Caxias do Sul, na data de 05 de outubro de 2019, realizada no espaço físico da Escola Municipal de Ensino Fundamental Professora Ilda Clara Sebben Barazzeti.

Dentre outras oficinas de transcriação promovidas nessa parceria, na oficina de Sonhografias de aula-tradução, ministradas pelas autoras, participaram 23 professoras da rede municipal de ensino de Caxias do Sul. As participantes autorizaram a divulgação de suas 
transcriações, já que a condição mínima da oficina era a de que cada sonho, feliz ou de angústia, fosse um sonho partilhável. Por questão de espaço, traremos quatro das transcriações.

Abaixo apresentamos sucintamente: a composição dessa Aula-tradução, as resultantes da aplicação-piloto dos dois métodos, de maneira intercambiante, bem como o roteiro da oficina, pontuando o uso de um ritmo de repetição a partir da escolha do famoso bolero de Ravel como disparador ao movimento de pensar sonhos com o corpo todo e, via rigor do intelecto, agir sobre a liberdade de signos a-traduzir dessa experimentação.

\subsection{Roteiro da Oficina}

Duração: 1 h e 20 minutos

Materiais e ambiente: disposição na sala (cadeiras) em roda, e iluminação à meia-luz. Haverá uma folha em branco (tamanho A3) no chão, um pincel e nanquim. Fichas e canetas para escritas individuais;

No quadro ou em um cartaz, as seguintes frases serão os inícios: "Sonhei que", "No sonho", “Acordei, mas voltei a dormir e sonhei que", "No meu sonho", "Foi um pesadelo, eu estava", “Acordei cansado(a), porque sonhei que", "Nunca me lembro dos sonhos, mas posso tentar dizer o que sinto sobre isso:", “O mesmo sonho veio-me mas de outra forma:”, "Tendo visto um sonho";

Som ambiente para ser sentido enquanto as participantes rememoram os sonhos e caminham movimentando-se livremente pela sala. Bolero de Ravel (1875-1997). Disponível em https://www.youtube.com/watch?v=Q4wb11w0ZHQ. Essa etapa é anterior à escrita e ocorre concomitantemente ao gesto com nanquim na folha em branco coletiva, gesto que cada participante extrairá a partir de um signo emotivo do sonho, que tenha sua tradução em um gesto informe.

Após, iniciar as explanações dos métodos.

Poema projetado, leitura individual e silenciosa: "Um Sonho", de Edgar Allan Poe (1809-1849), publicado no livro "Edgar Allan Poe — obra poética completa". Tradução: Margarida Vale de Gato. Disponível em: https://www.youtube.com/watch?v=7bSLXagAVWM. 


\subsection{Passo-a-passo}

1- 5 minutos: recepção e apresentação breve das ministrantes;

2- Até 10 minutos: participantes convidadas a levantar-se e a realizar um leve exercício corporal/gestual e de pensamento evocativo (do tipo memória afetiva) a partir de um sonho que desejarem compartilhar com as demais. Para tanto, ao embalo do ritornelo de Ravel, circulando livremente, cada uma vai desenhar no ar gestos que surgirem pela evocação onírica, até que um gesto se fixe, condense e simbolize as sensações sentidas pelo sonho. Assim que entender ter evocado suficientemente o sonho e definido um gesto correspondente, e tendo-o repetido algumas vezes para si, passará essa ideia gestual em uma pincelada única de nanquim na folha branca, disposta no chão (essa folha será a recolha dos gestos, um sonho coletivo da aula);

3- Até 10 minutos: cada participante, passará, a seguir, a escrever o sonho em uma ficha, começando com as frases sugeridas no quadro ou cartaz. As fichas serão recolhidas;

4- Até 15 minutos: leitura coletiva do poema "Os Sonhos". Relação entre sonho, pensamento e escrita poética na docência (sonhografia de aula, a-traduzir, arquivo);

5- 15 minutos: Poema de Poe sobre sonho. Exercício de escrita breve ("Meu sonho hoje é:”). Rigor intelectual. Poética de aula e Espiritografia. Leitura de cada frase;

6- 10 minutos: polinização cruzada dos sonhos escritos: cada um vai receber um sonho alheio para transcriá-lo na forma de poesia;

7- Leituras do sonho alheio e de sua tradução poética. Falas coletivas e questionamentos sobre as sensações sentidas durante o exercício de evocação e de transcriação dos gestos em pinceladas e na escrita pela linguagem.

\section{RESULTADOS}

Da elaboração transcriadora (o que fez cada participante com o sonho alheio): cada resultado formado com o sonho alheio, a transcriação para uma forma poética e a complementação da frase "Meu sonho hoje é..." (a transcriação e a complementação são da mesma pessoa). Assim devem ser lida as sequências: a) Sonho alheio recebido (iniciados ou 
não pelas sugestões do exercício sonhográfico)

b) Transcriação; e

c)

Resposta/complementação da frase "Meu sonho hoje é...".

\title{
5.1 Dança dos Elementos
}

Sonhei que os 4 elementos terra, água ar e fogo se encontraram para dançar. Primeiro a terra, firme e com pouca mobilidade recebeu o apoio da água, que aos poucos lhe trouxe certa suavidade. Em seguida, foi convidada para a dança com o ar, com leveza e sutilidade lembrou que a dança poderia ser harmônica. Por fim, o fogo achando tudo aquilo meio parado, impôs seu ritmo não considerando a natureza dos outros 3 elementos. Fim da dança!

Terra, água, ar e fogo juntos dançaram cada qual com suas particularidades A terra firme e dura recebeu a ajuda suava da água

Logo o ar entrou na dança com toda a sua suavidade tornou o movimento harmônico Mas o fogo queria mais intensidade e impôs um ritmo

Desconsiderou todos os outros

A dança acabou

Meu sonho hoje é...: Sonhei com o medo e ele me perseguia, me sufocava em sensações terríveis. Sonho em morar na praia; quero viver, mas com mais qualidade; só o mar poderá me trazer calmaria.

\subsection{Aromas do Esquecimento}

Dificilmente me lembro de meus sonhos. Isso é um pouco frustrante... Logo após despertar, eles vêm ao meu encontro e depois se dissipam como fumaça; se dissipam, deixando aromas e sensações no ar, mas que não consigo traduzir.

\author{
Cada noite \\ sonhos diversos \\ Ao amanhecer \\ Nada na lembrança \\ desperto \\ Sem perceber \\ Lá vão na fina fumaça \\ Dissipam \\ Aromas e sensações ficam
}




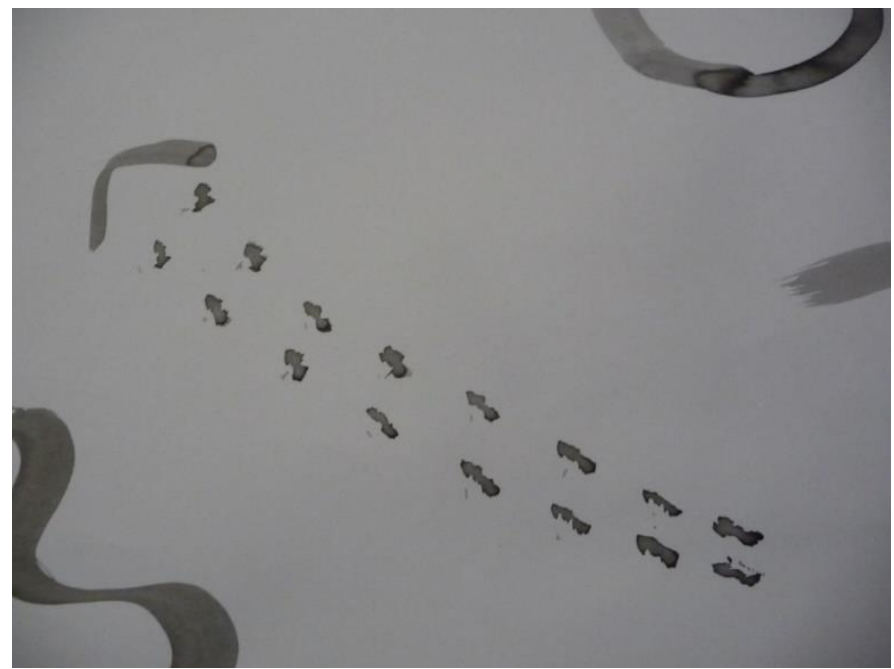

Figura 1 - Gestos coletivos em a-traduzir

Fonte: As autoras; excerto da Oficina Sonhografias de aula-tradução (2019).

Meu sonho hoje é...: A realidade é algo que pode assustar e desesperar e o sonho existe como alento. Por que sonhar? Para ter um objetivo, um rumo, pois sem desejo pode parecer uma vida vazia.

\subsection{Casamento}

Sonhei que chegou o grande dia do casamento da minha amiga. Conforme seu pedido, todas as madrinhas deveriam usar vestidos da cor rosa. Já eram 19h15min., e o casamento estava marcado para às 19h30min., só me restavam 15 minutos e quando me olhei estava com um vestido preto e completamente sem maquiagem. Entrei em pânico, corri para a casa da minha tia para ver se ela tinha algum vestido para emprestar, mas nenhum deu. Então encontrei uma solução, resolvi sonhar (dentro do sonho) que estava com um lindo vestido rosa, cabelo arrumado e maquiada, tudo perfeito para ir ao tão esperado casamento.

O sonho dentro do sonho, está aí, é para ser sonhado. uma fuga da realidade... um pesadelo ou um conto de fadas?
Um sonho de felicidade...

Uma busca de felicidade...

Um dia o sonho vira realidade!

Só o sonho!"

Meu sonho hoje é...: Sonho de hoje: Paz, serenidade e sabedoria. 


\subsection{Fugindo com meus alunos - responsabilidade - passeio de escola - Campo - gado} brabo - medo - pânico

Logo tudo se acalma - encontro abrigo para todos - tudo vai se acalmando - alunos mais calmos - respiração mais tranquila.

\author{
Muitas crianças, um lugar \\ O coração pulsa, as pernas coam \\ É um rebanho? Quase isso... \\ É mais, são seres pequenos \\ fogem, voltam, se divertem \\ Com a expressão da jovem mestra \\ Todos riem, explode o alívio
}

\author{
Estão todos aqui, e bem. \\ O abrigo do seu coração é grande para \\ todos \\ cabem? Sim, todos. \\ E voltam, eles juntos, e ela. \\ Formando o todo, da turma e sua \\ mestra.
}

Meu sonho hoje é...: Sonho com a vida mais leve, feliz. Cheia de seres com risos, inquietudes e ávidos pela busca.

\section{CONSIDERAÇÕES FINAIS}

A linguagem ainda precisa amadurecer diante dos sonhos. As participantes transcriaram emoções oníricas em sonhografias de aula utilizando o rigor espiritográfico. Portanto, partes atraduzir de suas vontades de docência-vida, formaram o resultado poético do qual trouxemos pequena amostra, incluindo a imagem final, produção coletiva dos rastros de pensamentos em sonhos, produzidos na oficina.

Afirmamos, com base nessa experienciação transcriadora que, mesmo em um breve acesso ao sonho, grande é o potencial da escrita. As transcriações resultaram de movimentos que o corpo transitou pela elaboração do sonho via rigor do espírito.

O broto poético em cada docente, evidente nessas composições que lemos, nos aponta que uma escrita de sonho e de poesia trata daquilo que rompe de maneira singular a terra enrijecida de imagens dogmáticas que muitas vezes permeiam o fazer aula. Pois como afirma Corazza (2019a, p. 32):

cada aula é um mundo. Cada mundo de aula é um encontro de vidas. Cada encontro de vidas é uma colheita de sonhos. Cada aula como mundo carrega 
um sonho implicado ou explicito. Logo, toda aula sonha. Sonha e cria mundos. E transforma a mentira da vida na verdade de um sonho.

Nessa experimentação espirito-sonhográfica, tangenciamos, portanto, as multiplicidades de pensar o sonho e de sonhar o pensamento. Num acesso na agoridade da Aulatradução, produzimos potências poéticas que ressonam sobre nossos currículos dormentes e didáticas insones. Essa criação auleira coletiva movimentou o Arquivo da Educação e, diante de olhos bem abertos, nos deixou outros rastros a-traduzir, os quais não se cansam de escriler em nossos corpos uma docência-pesquisa-vida.

\section{REFERÊNCIAS}

BORGES, Jorge Luis. O livro dos seres imaginários. São Paulo: Companhia das Letras, 2007.

CAMPOS, Maria Idalina Krause de. Espiritografias de cocriação dialógica. In: RODRIGUES, Carla Gonçalves (Org.). Caderno de Notas 5: arte, educação, filosofia. Oficinas produzidas em 2011. Pelotas: Ed. UFPel, 2013. p. 175-185.

CAMPOS, Maria Idalina Krause de. A Educação da Diferença com Paul Valéry: Método Espiritográfico. Projeto de tese - Programa de Pós-Graduação em Educação, Faculdade de Educação, Universidade Federal do Rio Grande do Sul, Porto Alegre, 2017.

CAMPOS, Maria Idalina Krause de. Paul Valéry educador. Porto Alegre: Ed. Mikelis, 2018.

CHEVALIER, Jean. Dicionário de símbolos (mitos, sonhos, costumes, gestos, formas, figuras, cores, números). 12.ed. Rio de Janeiro: José Olympio, 1998.

CORAZZA, Sandra Mara. Método Valéry-Deleuze: um drama na comédia intelectual da educação. In: CORAZZA, Sandra Mara. O que se transcria em educação? Porto Alegre: UFRGS/Doisa, 2013. p. 41-70.

CORAZZA, Sandra Mara. Projeto de Pesquisa de Produtividade (CNPq). Didática da Tradução, transcriações do currículo: escrileituras da Diferença (2014-2019). 2014.

CORAZZA, Sandra Mara. Projeto de Pesquisa de Produtividade (CNPq). A-traduzir o arquivo da docência em aula: sonho didático e poesia curricular. (2019 - 2023). 2019a.

CORAZZA, Sandra Mara. A-traduzir o arquivo da docência em aula: sonho didático e poesia curricular. Educação em Revista, Minas Gerais. 2019b, v. 35. Disponível em:

http://www.scielo.br/scielo.php?pid=S0102-46982019000100416\&script=sci_arttext . Acesso em: 27 jul. 2019. 
FOUCAULT, Michel. O corpo utópico. In: FOUCAULT, Michel. El cuerpo utópico. Las heterotopías. Buenos Aires: Ediciones Nueva Visión, 2010. p. 7-58.

FREUD, Sigmund. A interpretação dos Sonhos (I, 1900). Obras Completas de Sigmund Freud: edição standard brasileira. Rio de Janeiro: Imago, 1996.

FREUD, Sigmund. Dream Psychology Psychoanalysis for Beginners. The Project Gutenberg. 2005. Disponível em: http://www.gutenberg.org/ebooks/15489. Acesso em: 20 mar. 2020.

PAZ, Octavio. Signos em Rotação. 4. ed. São Paulo: Perspectiva, 2015.

POE, Edgar Allan. Histórias extraordinárias. São Paulo: Abril Cultural, 1978.

RANCIÈRE, Jacques. O inconsciente estético. São Paulo: Ed. 34, 2009.

REIS, Marina dos. Sonhografias de Aula. São Paulo: Pimenta Cultural, 2019a.

REIS, Marina dos. O sonho na concepção da imagem errante. Alegrar. n. 24, p. 9-18, ago/dez 2019b. Disponível em: https://alegrar.com.br/alegrar-24/. Acesso em 28 mar. 2020.

VALÉRY, Paul. Tel Quel I. Paris: Gallimard, 1941a.

VALÉRY, Paul. Mélange. Paris: Gallimard, 1941 b.

VALÉRY, Paul. Monsieur teste. São Paulo: Ática, 1997.

VALÉRY, Paul. Variedades. São Paulo Iluminuras, 2011.

VALÉRY, Paul. Lições de Poética. Belo Horizonte: Ed. Âyiné, 2018.

Recebido em: 07/05/2020

Aprovado em: 01/09/2020 